\title{
Urban Land Use Analysis and Policy Review of Ethiopia with Special Reference to Micro and Small Enterprise Development Initiative of Hawassa City
}

\author{
Addisu Sherbeza Woldemariam \\ Department of Urban Planning and Development, Ethiopian Civil Service University, Addis Ababa, Ethiopia \\ Email address: \\ addisusherbeza@gmail.com \\ To cite this article: \\ Addisu Sherbeza Woldemariam. Urban Land Use Analysis and Policy Review of Ethiopia with Special Reference to Micro and Small \\ Enterprise Development Initiative of Hawassa City. American Journal of Civil Engineering. Vol. 9, No. 4, 2021, pp. 99-117. \\ doi: $10.11648 /$ j.ajce.20210904.12
}

Received: May 30, 2021; Accepted: July 12, 2021; Published: July 22, 2021

\begin{abstract}
Micro and small enterprise in urban dimension is becoming the fundamental issue that lay a foundation to the structural transformation in to industrialized economy. The Ethiopian government has already developed firm commitment for the realization of the plan. However, the sector is not free from obstacles. The deterrent, apart from other things, facing the sector are shortage and unplanned expansion of working and selling premises. The main intention of the research is to investigate the contribution of urban land use plan as well as policy and legal frameworks towards the promotion of MSE. Descriptive approach is followed as the main designing of the research and Digital data collection is employed as a main method for capturing spatial data of premises. Questionnaires were distributed to a sample size of 269 MSE operators. Key informants were thoroughly discussed with help of semi-structured interviews. Document review was cautiously performed in the perspective of the promotion of Micro and small enterprises. Geographic Information System and AutoCAD were chosen as vital tool for depicting the spatial configuration of MSEs and the results were presented by using tables, maps, graphs and pie charts. The findings of the critical analysis elicited the assignment of working and selling premises for MSEs are carried out arbitrary and unplanned manner on public spaces. There are inconsistencies among urban policy, Strategies, urban plan manual and standard toward addressing the issue of MSE. To ensure sustainable progress in urban centers, the commitment of the government should not cease with the policy and strategy formulation. Rather, it has to go through manuals and standards since policies and strategies are eventually implemented by manuals and standards.
\end{abstract}

Keywords: Clusters, Incompatibility, Inconsistency, MSE, Spatial Distribution

\section{Introduction}

In cities across the globe, hundreds of millions of people exist in desperate poverty. Global poverty has become an urban phenomenon [1]. To be sure, poverty is a global phenomenon that occurs in every society. No nation is immune. In 20 industrialized countries, for example, over 10 per cent of the population, on average, was living below the poverty line [2].

According to International Labor Organization [3] by 2015, the people living below poverty line (earn $\$ 1 /$ day or less) is projected to be 809 million in the world. Out of which Sub Saharan Africa shares 404 million (42percent), Middle East and North Africa 8 million, Europe and Central Asia 7 million, China 73 million.

Reducing poverty is a headline goal in the international development agenda. The world has set a deadline for ending extreme poverty by 2030 [4]. The first of the Sustainable Development Goals is to end poverty in all its forms everywhere by 2030 . Reducing at least by half the proportion of men, women and children of all ages living in poverty in all its dimensions [5].

Many scholars and international institutions acknowledge the importance of Micro, small and Medium Enterprise in curving the economic challenges of the poor. Small and Medium Enterprises play a key role in national economies around the world, generating employment and value added and contributing to innovation. They are central to the efforts 
to achieve environmental sustainability and more inclusive growth [6]. They represent a significant part of the world economy and are one of the strongest drivers of economic development, innovation and employment [7].

There is increasing recognition that private sector development has an important role to play in poverty reduction. The private sector, including small enterprises, creates and sustains the jobs necessary for poor people to work and earn the income needed to purchase goods and services.

Much of the population in poor countries operates for Micro and small enterprise (MSE) and that even in richer countries; a substantial portion of the population is employed in small and medium enterprises [3].

The 20 million European Small and Medium-Sized Enterprises play an important role in the European economy. These are mostly micro-enterprises and in 2012 employed approximately 86.8 million people. This represents 66.5 percent of all European jobs for that year [8].

The dynamic role of small-scale industries in developing countries as engines through which their growth objectives can be achieved has long been recognized. Small scale industries in Africa account for 95 percent of employment and about 43 percent of the value added of the entire industrial sector. It is also estimated that small scale industries employ 22 percent of the adult population in developing countries [9].

In Ethiopia, Micro and small enterprise (MSE) is the second largest employment generating sector following to Agriculture. MSE contributes 3.4 percent of Gross Domestic Product (GDP), 33 percent of the industrial and 52 percent of manufacturing sectors [10]. About half of the urban workforce in Ethiopia is engaged in the MSE Sector and Addis Ababa nearly accounts for about 40 percent of the total operators in micro enterprise activities [11]. MSE created job opportunity for 6.2 million people on temporal and permanent base [12].

Despite the role played by Micro and Small Enterprise in contributing towards employment creation and economic growth, it has challenges that hinder from effective functioning of the sector. Although, the government has massively built working space for MSE in major cities and towns, working space still remains a critical challenge. The supply of working space is small relative to demand. The problem is not only shortage, working space are built arbitrarily [13].

Provision of working premise and selling place are among the critical challenges of MSE sector. There is a gap between demand and supply of land for enterprises. Similarly there is also acute shortage of sheds in manufacturing sector [14].

The contribution MSE in Ethiopia is very low when compared with that of other countries due to financial problem, lack of qualified employees, lack of proper financial records, marketing problems, lack of working premises and raw materials [15].

Although, the government has massively built working space for MSE in major cities and towns, working space still remains a critical challenge. Rent is extremely high in major cities especially Addis Ababa. The supply of working space is small relative to demand. The problem is not only shortage, working space are built arbitrarily [13].

Reviews of related studies indicate the challenges of MSE (working premise and market problems) can be solved through inclusive and participatory urban planning and revising the planning principles and standards in response to the prevailing local economic development endeavors.

The purpose of the study is to assess the land use plan with respect to MSE development and critically evaluate urban development policy and other legal documents in line with the ever changing role of city as a center of industrialization and tourism. Thus, the findings of study will have an impact on reducing the constraints of MSEs and maximizing the capacity of local governments through effective land use planning and scaling up the role of MSEs in promoting employment and reducing poverty. More importantly, the findings of the study will directly help the enterprisers who operate in urban centers through creation of working premises and creating market linkage to their products. The result of the findings will also fill the missing link and facilitates the smooth functioning of MSE Agency with other sectors.

\section{Micro and Small Enterprises Development Initiatives in the Urban Dimension of Ethiopia}

Micro and small enterprise (MSE), in urban area is becoming the fundamental issue that lay a foundation to the structural transformation in to industrialized economy. The Ethiopian government has already developed firm commitment for the realization of the plan. The effort along this line has started bearing fruits.

MSE is contributing vital role in sustaining economic growth and development in urban centers of both developed and developing countries like Ethiopia. The expansion of MSE has dual role. On one hand; it encourages creativity in any spheres of development. On the other hand, it ensures the transformation from Agriculture Led industrialization. Thus, expansion of Micro and small enterprises means hitting two birds with a stone. The sector continues to be in forefront position in stimulating local economy. By taking the irreplaceable contribution of MSEs, the government of Ethiopia zoomed eyes on the sector. However, apart from the government commitment, the sector is not free from deterrents that hinder the normal function of MSE.

The research conducted at country level so far confirmed production and selling premise is the critical challenges of Micro and Small Enterprise. The performance report of Growth and Transformation plan (GTP) of urban dimension of Ethiopia [16] shows that about 146 million square meters of land were expected to be prepared within five years and out of which 87.6 million of square meters of land were expected in the first three years (2011-2013) but the performance were only 33 million of square meters (37 
percent of the plan).

On the other hand, the demand for land for MSE is increasing from year to year rapidly. For instance the demand of land at national level were 4.73 million of square meters, 8.36 million of square meters, 19.18 million of square meters and 125 million of square meters for the years 2011, 2012, 2013 and 2014 respectively [12]. Similarly, the report made by Hawassa Trade \& Industry Department in 2014 depicts that the plan to prepare land for production and selling place for MSE were 387,311 square meters. However, the performance was only 106,304 square meters, which was only 27 percent [17]. The figures dictate that land provision is the major challenge of the sector.

The main intention of the research is to investigate the contribution of urban land use plan as well as policy and legal frameworks towards the promotion of MSE.

\section{Operational Definition of Micro Enterprises}

The working definition for Micro and small enterprises for urban centers are taken from the strategy of Federal Micro and small enterprises Agency published in, 2013.

The strategy classifies micro and small $\mathrm{s}$ enterprises in to two categories. These are micro enterprises and small enterprises. Furthermore, micro and small enterprises are classified in to two categories. These are industrial sector and service sector.

\subsection{Definition of Micro Enterprises}

\section{A, Industrial sector}

This sector includes manufacturing, construction and mining. Micro enterprises are defined as an enterprise that operates with 5 people including the owner and/or their total asset is not exceeding Birr 100,000 [16].

\section{$B$, Service sector}

Service sector includes activities such as retailer, transport, hotel and Tourism, Information Communication Technology and maintenance service. Micro enterprises are defined as an enterprise that operates with 5 persons including the owner of the enterprise and/or the values of total asset is not exceeding Birr 50,000 [16].

\subsection{Definition of Small Enterprises}

\section{A, Industrial sector}

This sector includes manufacturing, construction and mining. Small enterprises are defined as operates with 6-30 persons and/or with a paid up capital of total asset of Birr 100,001 and not exceeding Birr 1.5 million [16].

\section{$B$, Service sector}

Service sector includes activities such as retailer, transport, hotel and Tourism, Information Communication Technology (ICT) and maintenance service. Small enterprises are defined as operates with 6-30 persons or/and total asset, or a paid up capital is with Birr 50,001 and not exceeding Birr 500,000 [16].

\section{Description of the Study Area}

Hawassa city is the capital of two regions (provinces), Southern Nations, Nationalities and people's regional state as well as Sidama Regional state. Hawassa city is situated along the international road that connects Addis Ababa with Nairobi at a distance of 275 kilometers south of Addis Ababa.

According to Central Statistical Agency [18], the total population of the City Administration is 328,875 and out of which 169,186 is male and 159,689 are female.

The City administration has divided in to 8 Sub-Cities (one rural and seven urban) and 32 Kebeles, These Eight sub Cities are Hayek Dare, Menehariya, and Tabor, Misrak, Bahile Adarash, Addis Ketema, Mehal Ketema and Hawela-Tulla (Rural).

The city is located on the geographical co-ordinates of about $07^{\circ} 03^{\prime}$ North latitude and $30^{\circ} 29^{\prime}$ East longitudes.

The city is established on relatively flat plain areas with an average elevation of about 1,690 meters above sea level. The city is situated within the Rift Valley. The city experiences 'Kola' climate with the annual mean temperature and rainfall $20^{\circ} \mathrm{C} \& 78.9 \mathrm{~mm}$.

Hawassa city is situated in Hawassa sub-basin drainage system, having seasonal and perennial rivers such as Tukur Wuha River that collect water from the nearby high land areas and eventually drain it to Lake Hawassa.

\section{Research Method}

The work plan for conducting the inquiry is established based on the evidence that helps to answer the research questions for the title under investigation. Descriptive approach is followed as the main designing of the inquiry and it is selected because the main intension of the study is to explain or describe the characteristics of existing realties in relation to MSE. Similarly, the paper compares and contrasts the spatial configuration of Enterprises with the existing integrated development plan.

Table 1. The revised definition micro and small s enterprises in Ethiopia.

\begin{tabular}{llll}
\hline Level of Enterprise & sector & Manpower & Total asset \\
\hline \multirow{2}{*}{ Micro } & Industry & $\leq 5$ & $\leq$ Birr $100,000(\$ 6000$ or E4500) \\
& service & $\leq 5$ & $\leq$ Birr $50,000(\$ 3000$ or E2200) \\
\multirow{2}{*}{ Small } & Industry & 6 & Birr 100,001- 1.5million $(\$ 90000$ or E70000) \\
& service & 6 & Birr50,001- 500000 (\$30000 or E23000) \\
\hline
\end{tabular}

Source: [16] 

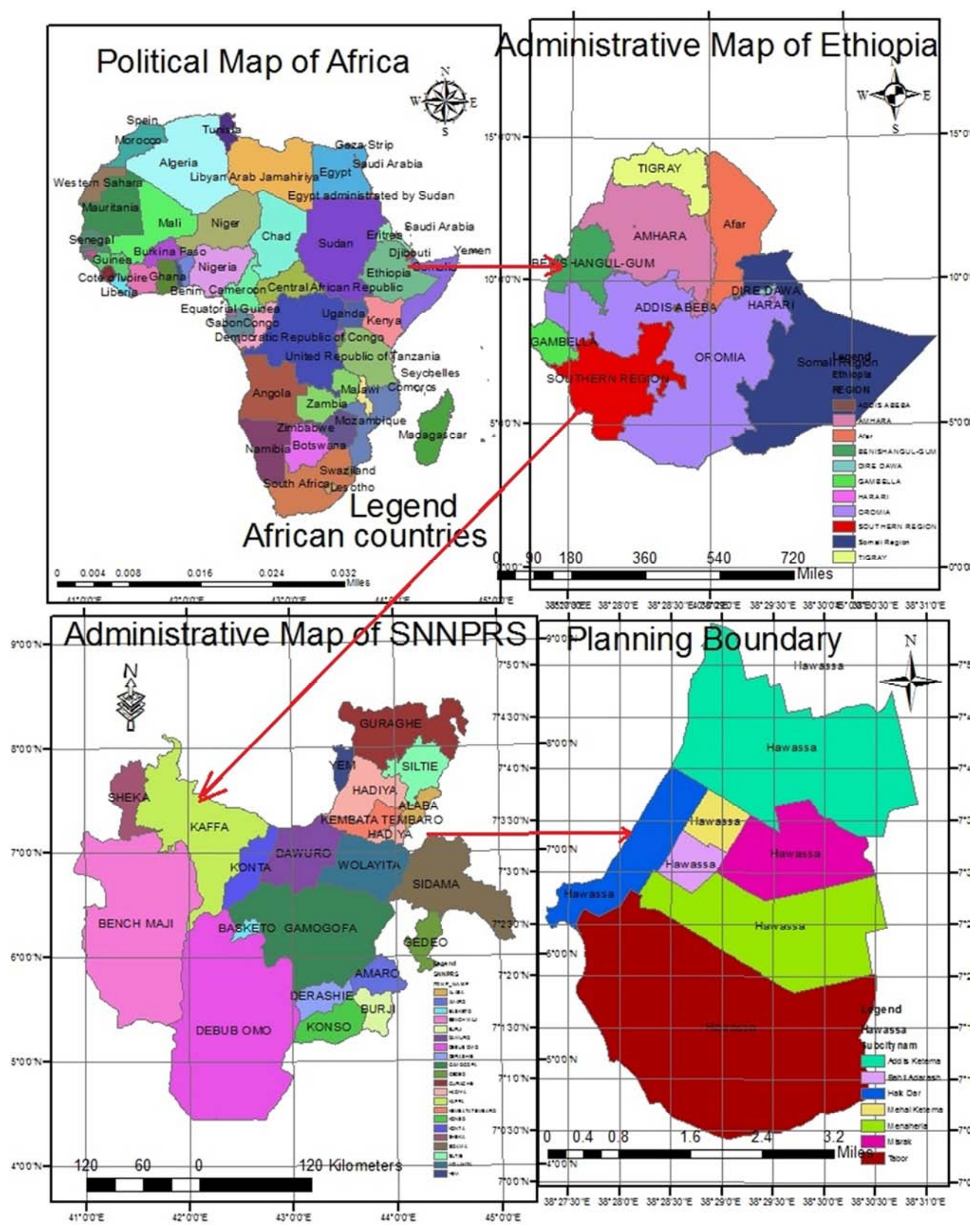

Source: Computation of GIS, 2021

Figure 1. Location of Hawassa city Administration.

Handle Global Positioning System was taken as the vital spatial data capturing instrument. Questionnaires were also preferred to collect data from MSE operators while semi structured interview was adopted as the main instrument for 
data collection from Government officials and experts.

Both probability and non-probability sampling procedures were applied in this research.

Probability sampling technique more specifically, stratified sampling technique was employed so that each category of MSE has the equal chance of being selected and represented proportionally and the problem of omission of the five categories is avoided. Thus, from each of the five strata or categories (Trade, Construction, Agriculture, Manufacturing and service), proportional number of enterprises was selected and questionnaires were administered to them. Non probability sampling techniques was also used to fill the data gap that will not be covered by probability sampling technique. Purposive or judgmental sampling was selected as the main instrument for data collection from officials and experts who are engaged in Micro and small enterprise offices.

The researcher distributed a total of 272 questionnaires to operators of enterprises. From the distributed questionnaires 270 were returned. In the process of crosschecking the validity, one questioner, out 270 , was not properly filled and was not reliable and thus discarded. Therefore, the information from 269 questionnaires was employed for the research. The response rate to this survey was 99 percent. Besides, to examine the challenges and prospects of the sector, seven officials and experts from MSE offices of seven sub cities and one (head) at city level were contacted and the response rate is 100 percent. On the other hand, all of the spatial data (686 establishments) for working and selling premises were acquired. Therefore the data obtained are valid and reliable enough for carrying out the analysis.

\section{Results and Discussion}

\subsection{Land Use (Spatial Aspects) Analysis Results of MSE}

\subsubsection{Trend Analysis of MSE}

According to the information received from Hawassa city Trade Department (2015), from 2010 -2015, MSE contribute job opportunity for 46,297 peoples on permanent base and 86,872 peoples on temporal base. On the other hand, the numbers of enterprises by year 2008 were 81 and this number grew to 629 by the year 2013. The land demand is also shows an increasing trend within five years. The figures below confirm the remarked growth in provision of premises for Micro and small enterprises in the city. The provision of land for MSE by year 2008 was 16,520 meter square and the provision grew to 197,847 meter square after six year.

Table 2. Trends of establishments and area occupation by MSE for 6 years.

\begin{tabular}{llllll}
\hline YEAR & $\mathbf{2 0 0 2}$ & $\mathbf{2 0 0 3}$ & $\mathbf{2 0 0 4}$ & $\mathbf{2 0 0 5}$ & $\mathbf{2 0 0 6}$ \\
\hline Actual area delivered (M2) & 16,520 & 64,335 & 70,268 & 18,526 & 106,304 \\
No. of establishment & 81 & 135 & 127 & 249 & 57,847 \\
\hline
\end{tabular}

Source: [19]

\subsubsection{Areal Distribution of MSEs by Growth Oriented Sectors}

The existing information collected from all MSEs having any sort of premises with the help of handle GPS reveals trade subsector shares more than half of the total in terms of areal coverage and followed by service subcategory.
The analysis through GIS reveals the existence of 86 buildings in the city constructed for the purpose of manufacturing activities, 198 for service and 43 for urban agriculture. As it is observed during field survey, one building on average accommodates 2-3 operators/associations depending on the types and the maturity level of the enterprises.

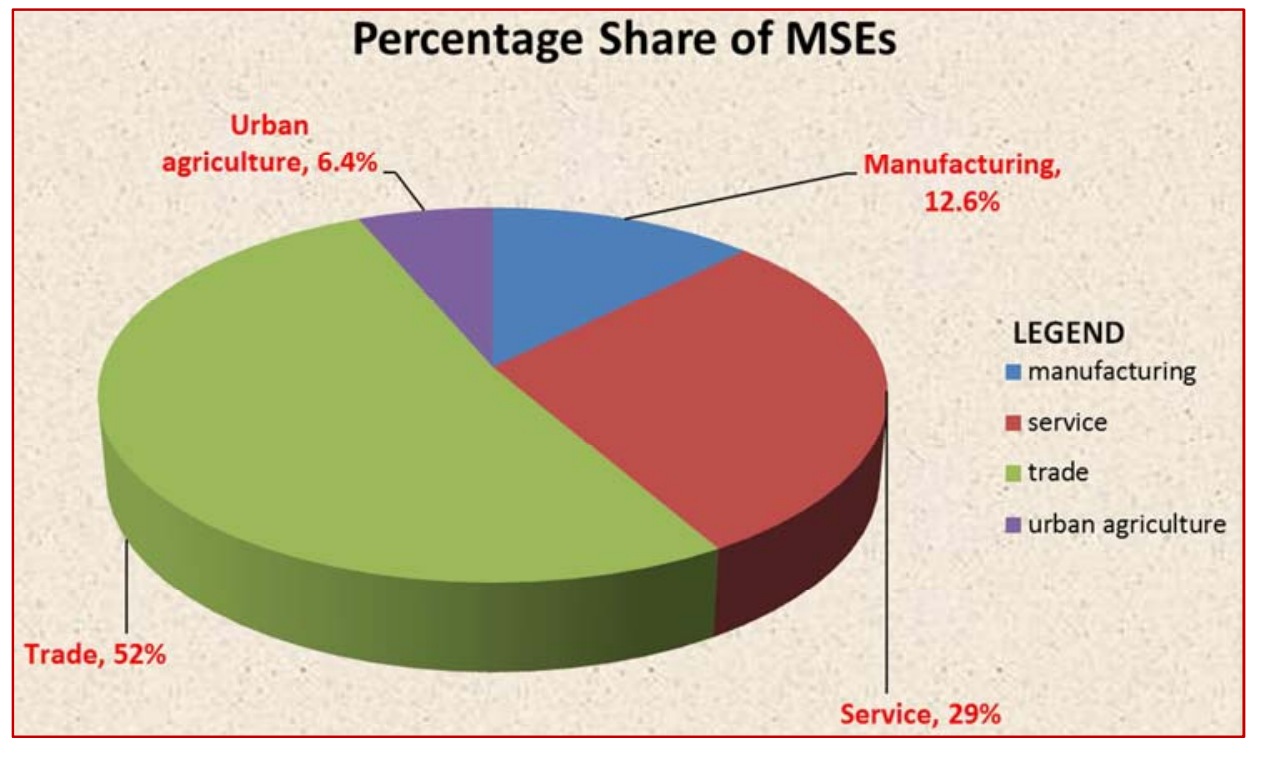

Source: Field survey and GIS

Figure 2. Proportion of Area by subsectors in Hawassa city (2015). 
Table 3. Proportion of area based on the land use plan by subsectors in Hawassa city (2015).

\begin{tabular}{llll}
\hline object id & category & count & Total area $\left(\mathbf{m}^{\mathbf{2}}\right)$ \\
\hline 1 & manufacturing & 86 & 26546 \\
2 & service & 198 & 9638 \\
3 & trade & 355 & 4441 \\
4 & urban agriculture & 43 & 49497 \\
5 & Sunday market & 4 & 715 \\
& Total & 686 & 90837 \\
\hline
\end{tabular}

Source: Field survey and GIS

As indicated on the above, out of the total area occupied by MSEs, trade subsector contributes 52 percent and followed by service (29 percent) and manufacturing (12.6percent). Urban agriculture shares only 6.4 percent.

\subsubsection{Spatial Distribution of MSE by Place of Origin}

Results of analysis points out the level of land use plan making and implementation. Most of enterprises are situated together with other establishments and very small proportion is placed independently. Micro and small enterprises are placed along the street, lake buffer and on the space reserved for open space.

Out of the total enterprises in the city, 435 (63 percent) are found along street, 77 (11 percent) with in lake buffer, 53 (7 percent) with in the space reserved for green and there are only 118 (17 percent) are situated independently of other land uses. On the other hand, there are also four temporal markets (usually called Sunday market). Sunday market is the type of temporal selling place and usually conducted on selected asphalts by blocking circulation during Sunday. For the purpose of the study, four main sties of temporal market are identified and located on land use map.

The above figure designates unplanned expansion of MSE within the city. Most of the enterprises are placed along the sides of street by obstructing pedestrian movement.

The figure also points out the assignment of premises for Micro and small enterprises are carried out arbitrary on public spaces. This in turn diminishes the role played by Micro and small enterprises public spaces such as streets and green frames.

\subsubsection{Spatial Distribution of MSE by Function of Premises}

The result of findings through GIS verifies the uneven distribution of production and selling places in the city. Working premises contribute only 12 percent (87establshments) of the total establishments. The largest share, 563 establishments (82 percent) is accounted by selling premise. Premises serving for both production and selling account 5.2 percent (36 establishments) and this type is dominantly found in clusters and shades of Addis Ketema sub city.

There is severe shortage of selling premises for those engaged in manufacturing activities. This reality is over emphasized during interview with key informants and operators. Except, those situated in Addis Ketema and Menaheriya (I.e. around Atote), all the clusters and shades lack selling premises and are situated far from market and raw materials.

The above figure denotes, despite the great dedication by the government to promote the manufacturing subsector, it is found in small proportion. Manufacturing establishments are confined in to clusters and shades situated in seven sites. The existing reality dictates that one cluster accommodates from 12 up to 28 operators depending on the areal coverage. From this fact it is possible to imagine the scarcity of clusters. On the other hand, the existing working premises are not accessible to market and raw materials. Five of the seven (60percent) clusters are situated away from threshold population and raw materials.

\subsubsection{Spatial Distribution of MSE by Construction Material}

As far as the existing working and selling premises of the city is concerned, cluster buildings account 10.7 percent, shade 2 percent. Whereas temporal options take the largest share. temporal options comprises container, lumber, wood, wood \& mud, plastics, Sunday market with percentage of $17.4 \%, 54 \%, 3 \%, 2.9 \%, 7.7 \%$ and $0.5 \%$ respectively.

About 87 percent of the enterprises are constructed either with container, lumber and wood\& mud. Only 12.7 percent of establishments are occupied by clusters and shades.

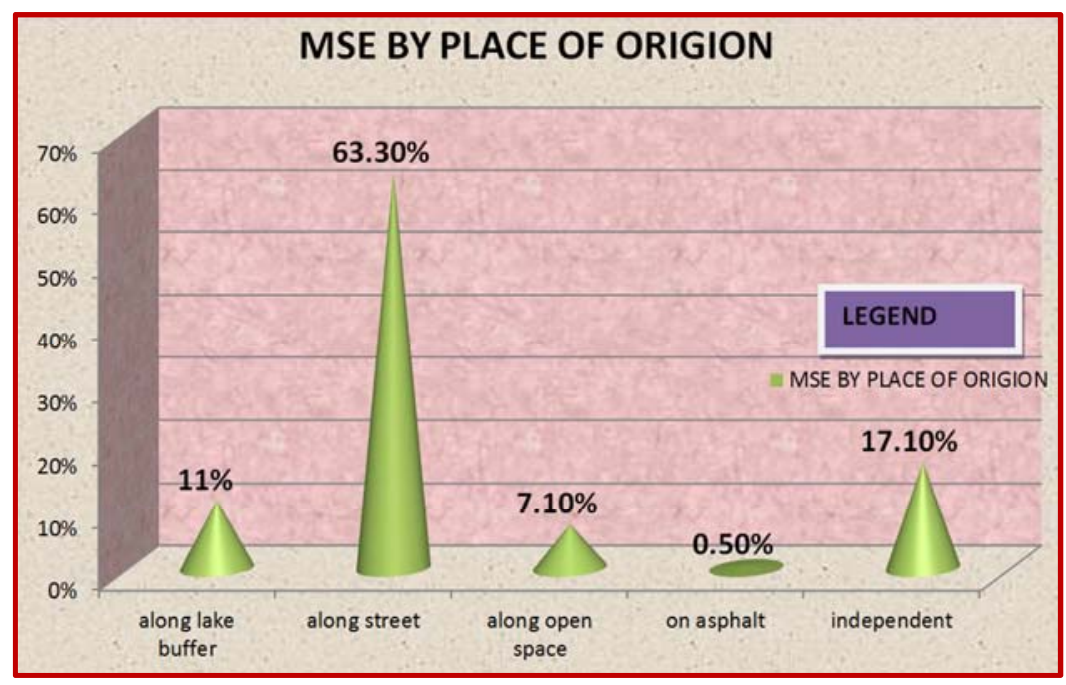

Figure 3. MSEs by place of origin. 


\section{LOCATION OF MSE OF HAWASSA}

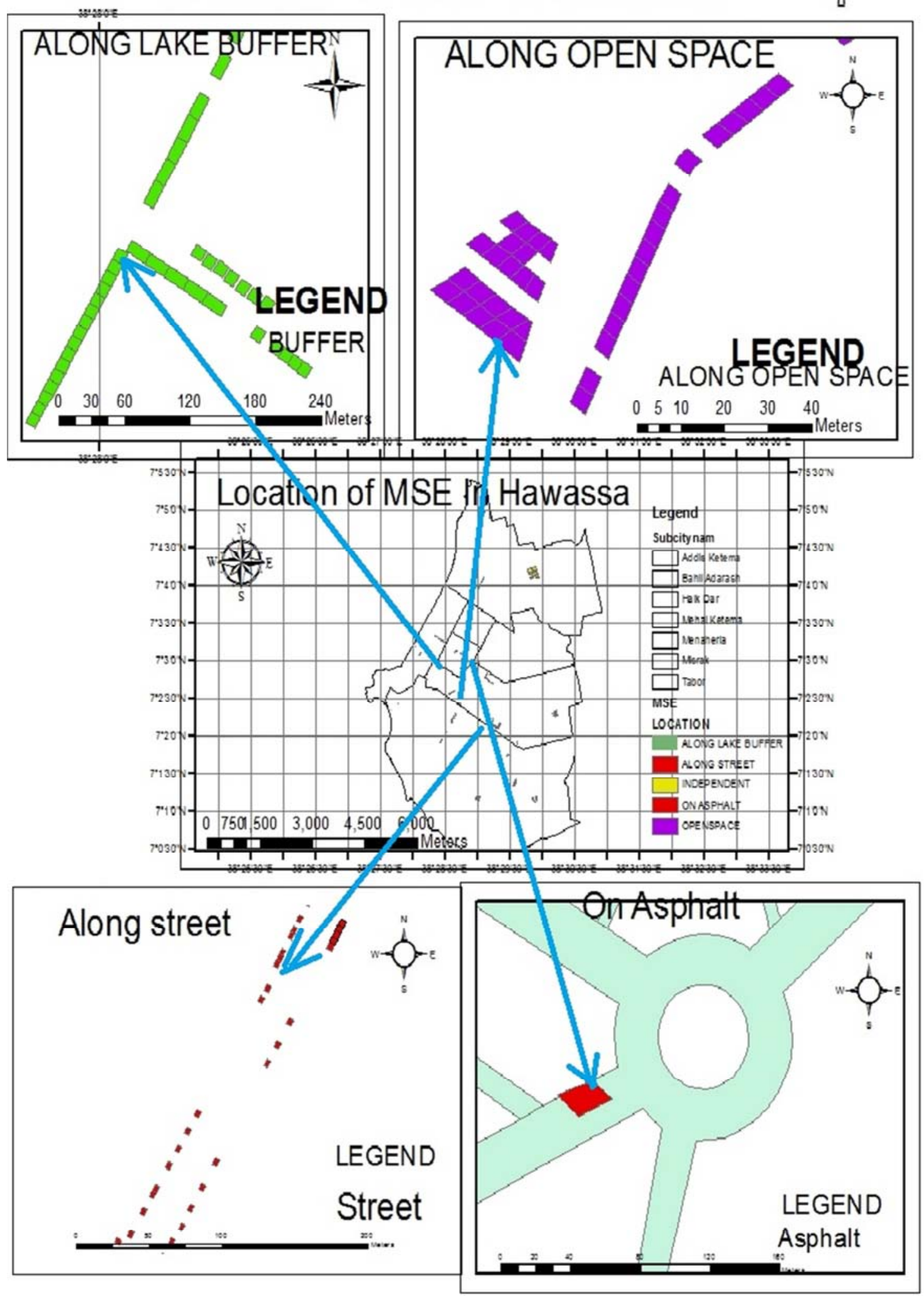

Source: Field survey and GIS

Figure 4. Spatial distribution of MSE by location. 


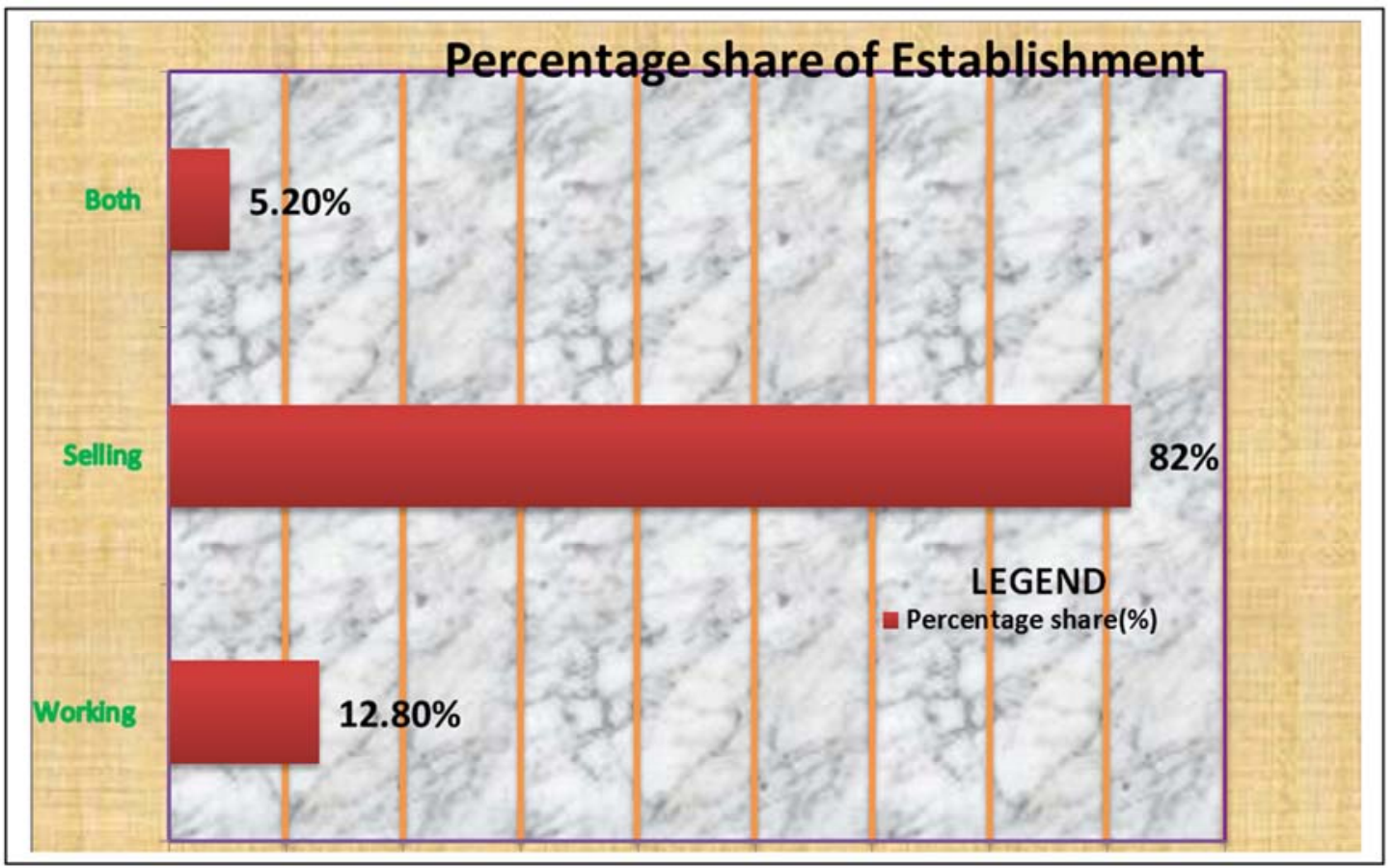

Source: Field survey and GIS

Figure 5. Spatial distribution of MSE by Premise type.

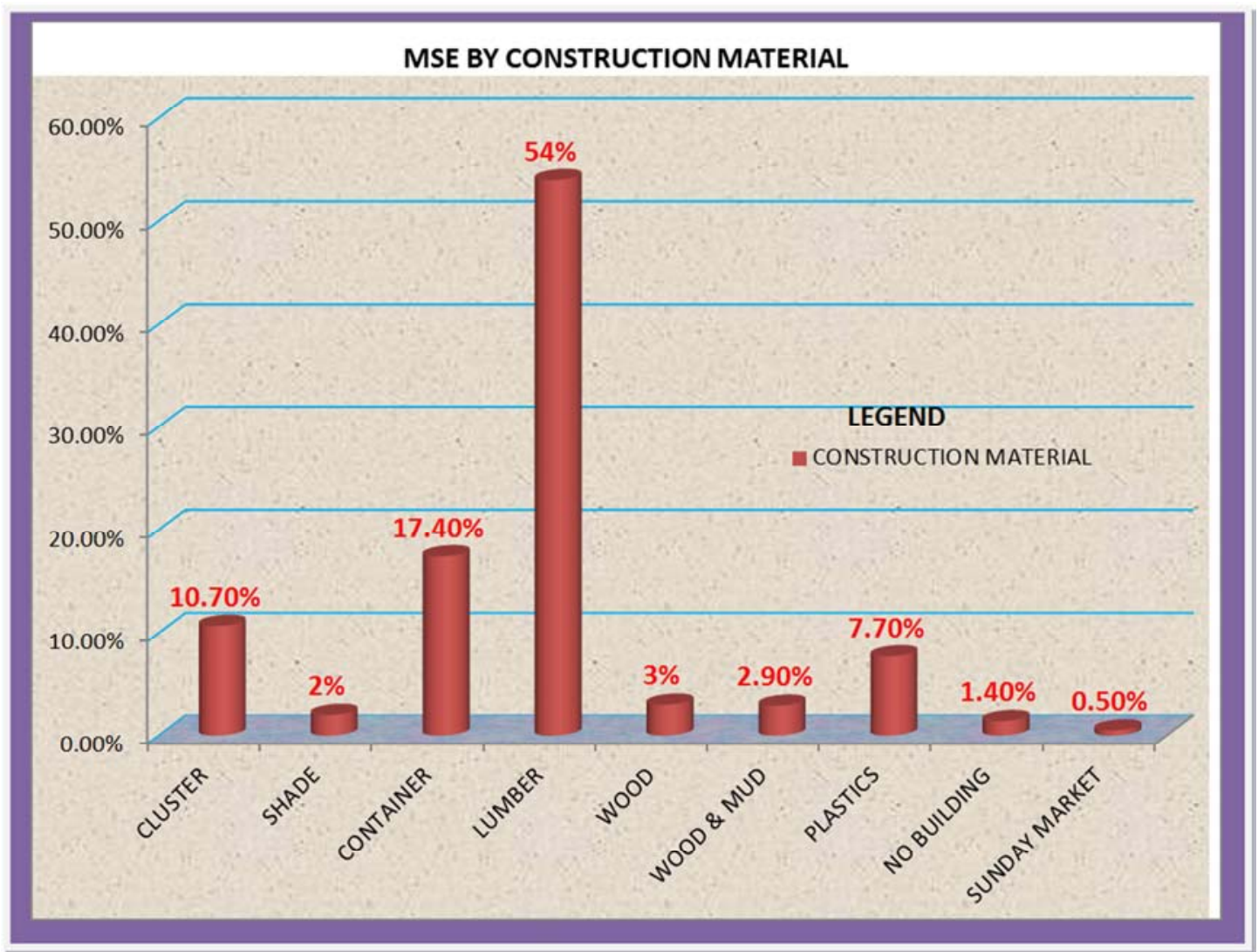

Source: Field survey

Figure 6. Spatial distribution of MSEs by building type.

The above figure illustrates the premises made from container and lumber share more than 72 percent from the total establishments. Furthermore, there are 120 containers (17.4 percent), serving for selling premises. 


\section{Spatial distribution of MSE by construction material}

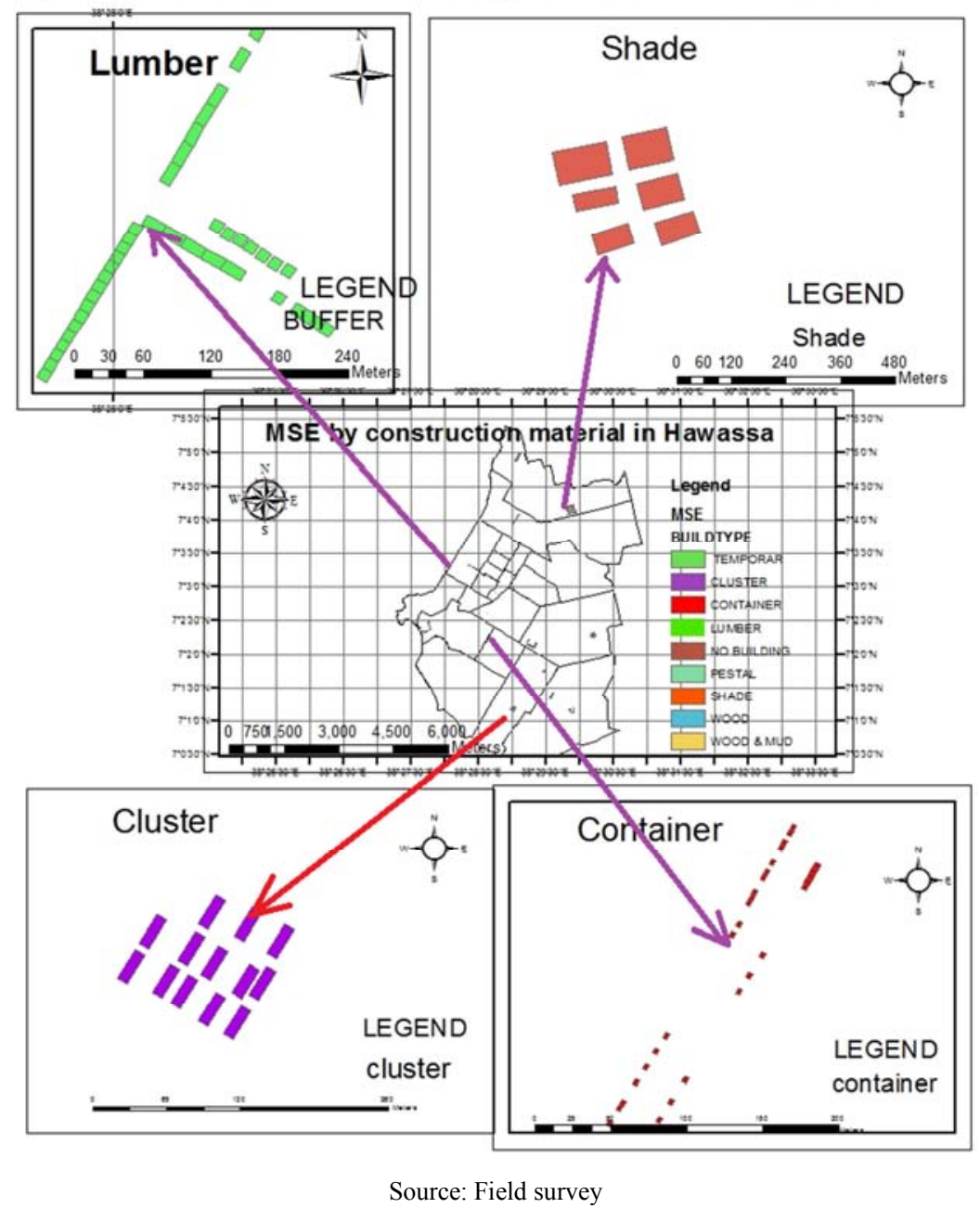

Figure 7. Spatial distribution of MSE by construction material.

The above figure designates the concentration of similar establishments on the same places. Selling premises made from lumber are confined to Lake Hawassa. Similarly, containers are concentrated in places such as "SeferSelam" and near to Tabor primary school. Due to the nature of the trade, selling premises situated near to bus station are typical made from wood and are left open. The dominant trade type in this place (bus station) is retail and specifically fruits and vegetables are commonly sold. On the other hand, clusters are situated around seven sites in the city and 60 percent of them are found near to peripheries of the town away from thresh hold population and inputs for production purpose.

\subsubsection{Compatibility of Premises in Line with IDP and Adjacent Land Uses}

To assess the compatibility issues of the existing working and selling premises, acceptable criteria are selected for the matter of convenience. One of the criteria adopted is by taking the Integrated Development Plan (IDP) of Hawassa as the reference frame and thus, any establishments that are constructed in according to the IDP are taken as compatible and otherwise incompatible. The second criterion is compatibility matrix for MSEs, taken from the Urban Planning Preparation and Implementation standards set for the location of Micro and small enterprises as listed below;

\section{(i) Compatibility matrix for MSEs}

The compatibility matrix, as indicated on the Urban Planning Preparation and Implementation standard, elaborates the land use functions such as mixed, manufacturing and storage, as well as transport are compatible and thus will be planned along with MSEs. On contrary, MSEs could not be planned together with green frame and service establishment such as schools and health institutions.

Table 4. Compatibility Matrix for MSE.

\begin{tabular}{ll}
\hline Land use & MSEs \\
\hline Mixed & $\sqrt{ }$ \\
Center & $\sqrt{ }$ \\
Manufacturing\& storage & $\sqrt{ }$ \\
Green frame & $\times$ \\
Service & $\times$ \\
Transport & $\sqrt{ }$ \\
\hline
\end{tabular}

Source: [20] 


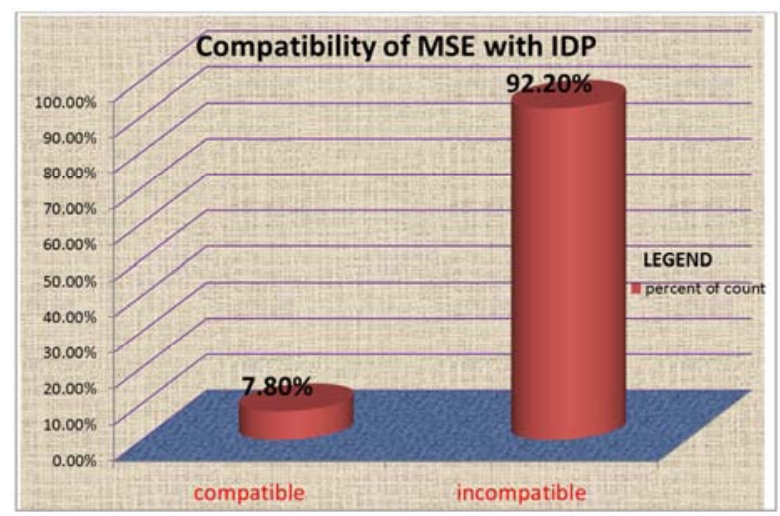

Source: Field survey

Figure 8. Compatibility of enterprises with IDP of Hawassa City.

\section{(ii) Compatibility of Premises vis-à-vis IDP}

By taking the Integrated Development Plan of Hawassa as the reference frame, the existing working and selling premises are categorized in to two groups.

The results of analysis through GIS confirms, out of the total premises, 632 are incompatible with the Integrated Development Plan of Hawassa. This implies 92 percent of the existing working and selling premises are incompatible and only 8 percent (54 establishments) are constructed according to the plan.

The figure discloses the existence of land use conflicts in the process of establishment of both working and selling premises. The special emphasis given by local government for the expansion of MSEs partly ignores the proper implementation of Integrated Development Plan (IDP) of city.

The map below gives a picture of incompatibilities of Micro and small enterprises with respect to Integrated Development Plan of city. A clear testimony of incompatibilities is the violation of open space and public spaces. As it is represented above, most of MSEs are located on the sides of the streets and this implies their establishment inhibits pedestrian movement and in turn make the people to use the main asphalt together with vehicles. It has adverse effects such as disturbing the circulation. Similarly, MSE establishments closer to Lake Hawassa, along green frame and closer to services (like educational and health institution) are against the land use plan and urban planning standard.

\section{Incompatibilities of MSEs}

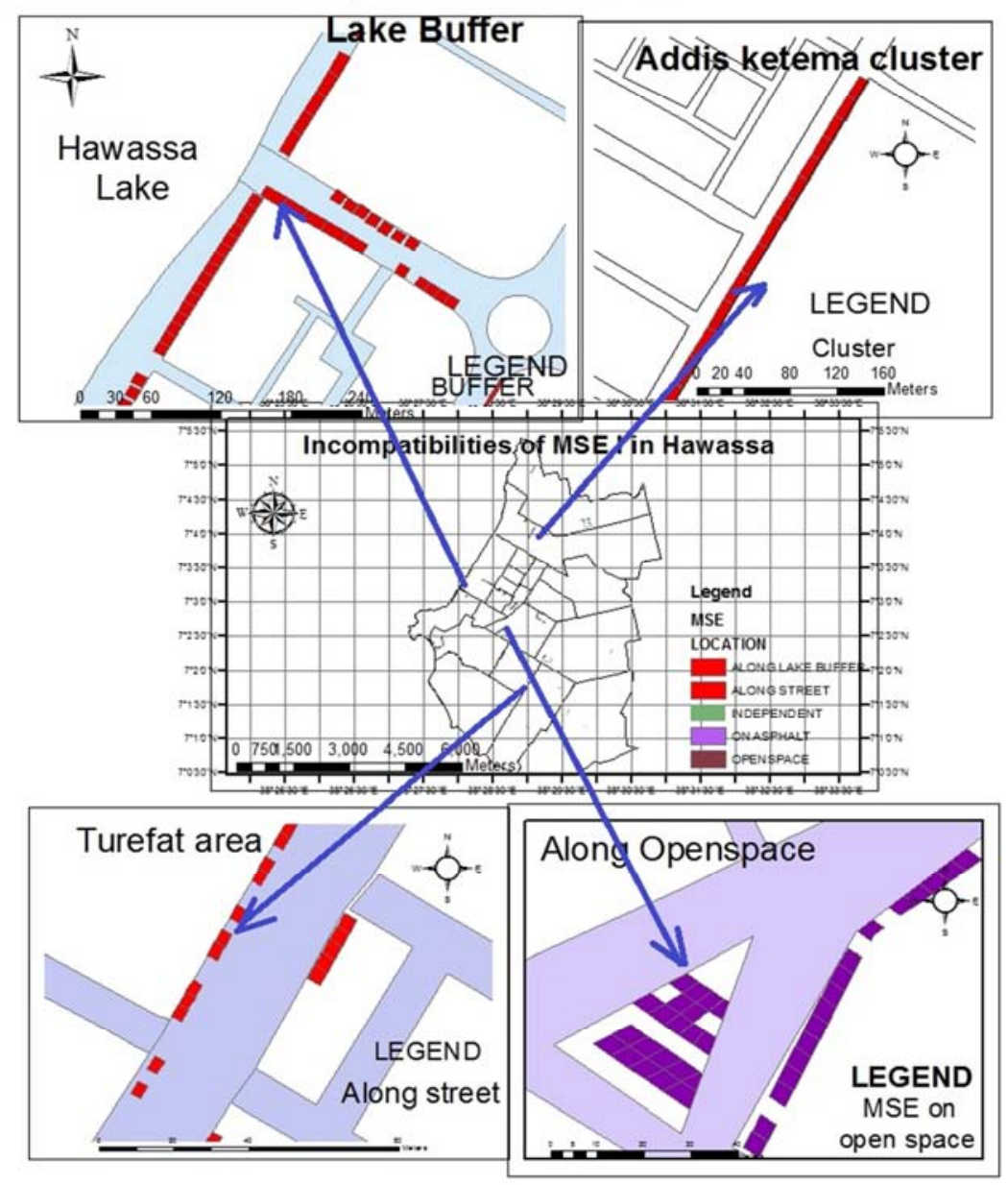

Source: Field survey

Figure 9. Incompatibility of MSEs with IDP. 


\subsection{Policy Analysis in the Perspective of MSE}

The government of Ethiopia so far enacted multifaceted policy and legal documents (proclamations, rules regulations, guidelines and manuals) with the intension of creating on enabling environment for MSE to play the leading role in curving poverty and unemployment as well as ensure economic transformation in urban areas.

Both Sidama region and Hawassa City Administration did not have their own policy and legal document formulated at regional and local level regarding MSE. Rather, both are applying those policies and legal documents formulated at Federal level. Therefore, the researcher reviewed the policy and legal framework enacted at federal level since these policy and legal documents are functioning in the region in general and in Hawassa to the specific.

The review of policy and legal frameworks were conducted with the special emphasis to their responses to working and selling premises for MSE. The researcher also undertook semi structured interview with key informants to crosscheck whether there is any loophole in policy, legal documents and institutional framework that inhibit the effective functioning of the sector, the documents which are directly linked to working and selling premises as well as Government support services to MSEs are selectively and thoroughly assessed. To this end, Urban Development Policy, Micro and Small Enterprise Strategy, Urban planning and Implementation Strategy, Urban planning and Implementation manuals and Standards are carefully reviewed in line with the expansion of Micro and Small Enterprise in urban centers.

\subsubsection{Review of Urban Development Policy in Line with MSES}

The revised policy document of Urban Development, issued 2013 acknowledges the importance of MSE in curving urban poverty and unemployment. It is clearly stated in the policy document as'. Urban centers in the country are in deplorable poverty, which become residential centers of jobless people. The urban centers in the country could not serve as organized and developed centers of market, industry and services.'

The policy elaborates the need for expansion of MSE to redress the challenges of urban centers as follows.

"The focus of urban development in Ethiopia should be on the expansion of MSE. It is because such institution plays a key role in urban poverty reduction and bringing about accelerated and sustainable development" [21].

The policy points out the major challenges of MSE to be marketing Problem, lack of managerial skill, financial constraints and land and infrastructure facilities. The policy particularly prescribes the solutions to solve the problems of land and infrastructure facilities as'

1) Preparing land with adequate infrastructure facilities, identifying those suitable for Micro and small business institutions and leasing to the institutions at reasonable price.

2) The construction of shades with production facilities on the prepared land and lease to micro and small business institutions or facilitate mechanisms by which the institutions lease the developed land and construct the shades as per their own design by maintaining the standard.

3) Encouraging and organizing micro and small business institutions engaged in similar type of activities on such developed land by giving them priority in training and credit services of machinery and equipment and coordinating their activities to create inter linkages.

4) Allocating pocket areas within kebeles and villages as appropriate to micro and small business operators who could not be organized by coming together.

The policy also assures in the preparation of developed land the priority should be given for industries and MSEs and following this land for housing, business and services continues

Despite the detail elaboration of policy directions towards MSE, there is mismatch between policy and micro and small enterprises strategy. For instance the micro and small enterprises strategy inhibits the delivery of undeveloped land for micro and small operators.

\subsubsection{Review of Micro and Small Enterprises Strategy}

Micro and small enterprises strategy of Ethiopia [16] elaborates the given by the government industrial development plan as' since MSEs are the main source of urban employment creation and employment creation in turn is the fundamental engine for economic development, the government gives utmost effort for the sustainability of the sector'. The strategy recognizes MSE as an incubation centers for private investors.

Cognizing the irreplaceable role played by the sector in addressing the pressing needs of the society, the government has already created an enabling environment for the expansion of the sector.

The strategy stipulates the commitment of the government in scaling up of annual budget in urban centers for the construction working and selling premises as' the government is continuously assigning more budget for capital expenditure (next to education and training) for establishment of clusters and shades as well as for purchase of machinery for processing raw materials'.

The strategy document points out the compatibility issues in construction of clusters and shades. The construction of working and selling premises takes in to account the appropriateness of place, topography and centrality.

On the other hand, the strategy acknowledges market problems as one of the major challenges of micro and small enterprise. It elaborates market problems is linked with lack of competitiveness, in production of demand driven goods and services and this problem is solved by operators themselves. The government has to provide working and selling premises, bazaars and exhibition centers to facilitate the link between producers and consumers.

As it is noted in the document, since 2013, a total of 34 million meters squares of land is delivered to micro and small 
enterprise. Within the stated period, more than 8000 working and selling premises as well as 380 buildings have been constructed and transferred to the operators.

Further, the strategy pinpoints, the major challenges encountered so far in the construction of clusters and shades in urban centers as'

1) The construction of working and selling premises was partly not in accordance with master plan, without site plan, inconformity of design, lack of infrastructure and the amount of land and buildings were incompatible with the nature of enterprises and product type.

2) Enterprises within clusters and shades were not selected based on product chain and there was lack of clear information about monthly rent as well as duration for enterprises within clusters and shades.

3) Clusters were prepared in a way that did not ensure market linkage and technological improvement.

The above challenges were identified during field survey and semi structured interviews with key informants. Land use analysis section also approves the incompatibilities and inappropriateness of clusters and shades in the city as compared to Integrated Development Plan.

Further, the strategy sort outs the challenges in detail by classifying micro and small enterprise in to three categories based on maturity levels (start up, growth and maturity stages). It reveals the challenges at lunching or start up stage to be lack of capital, lack of accounting, business management, lack of skills and techniques.

The challenges at growth stage to be lack of working and selling premises, lack of capital, lack of accounting, business management, lack of skills and techniques and the challenges at maturity stage to be lack of working and selling premises, lack of capital, lack of accounting, business management, lack of skills and techniques.

As it is noted on the strategy document, there is the shift in support service delivered by the government from mass support to selective to each growth stage. Therefore, the government will continue on providing cluster and shades, apart from other things for enterprises at growth and maturity. The implication is that new enterprises that join the sector will not get the support from the government in terms of working and selling premises unless they are transferred to the second (growth) stage.

The strategy ignores the working and selling premises as the major challenges at lunching stage. However, the discussion with operators and key informants reveals working and selling premises as the critical challenges at lunching stage.

Despite, the challenges of operators vary depending on the level of maturity, enterprises at three stages shared working and selling premises as the common problem and even the Urban Development Policy support the notion that enterprises, irrespective of their level face the problem of working and selling space.

On the other hand, the strategy point outs the specific support packages provided by the government in order to promote the role played by enterprises and curving the existing challenges of working and selling places and market problem in sustainable manner. The strategic directions towards expansion of support services on market development and trade to enterprises by government as it is elaborated as'

1) Cluster development will continue in urban centers and it is implemented in accordance with Urban development (structure) Plan

2) Standardized clusters will be prepared for both production and selling for those enterprises requiring large space and liable to health risk in the process of production

3) Permanent standardized exhibition centers that serving for the promotion of goods and services for MSEs will be established in urban centers

4) Selling places will be prepared along the residential areas for those enterprises by their very nature take part in subsistence life and could not be collected in clusters

5) Enterprises at any stage will pay reasonable rent for both working and selling premises

6) The construction of clusters will be conducted in accordance to urban plan and national standard for clusters as well as in suitable places for infrastructure provision

Further, the strategy emphasis cluster development will be undertaken aiming at avoiding the delivery of land to operators mainly to reduce the cost for expenditure. It points out the establishments of clusters take in account the nature of enterprises and implemented with active involvement of beneficiaries.

The strategy discharges the mandate of preparing the developed land for MSEs to the respective Regional Urban Development Bureaus and it urges prior to the development of clusters, site plan that is compatible with structure plan should be prepared.

\subsubsection{Review of Urban Planning Legal Documents in Line with MSE}

Urban plan guides the overall development activities of any urban centers. The location of industries, micro and small enterprise as well as their number is determined by planning. This in turn is influenced by the availability and the quality of legal document such as Urban Planning Proclamation, Urban planning and implementation strategy, Guidelines, manuals and standards. In this section whether the urban planning documents and principles are compatible with other micro and small enterprise policies and discharging their leading role in reducing urban poverty and unemployment through promoting the sector or not is reviewed. The level of flexibility and timeliness of urban planning principles and standards are assessed in line with MSE development agenda of the government.

\section{(i) Review of Urban Planning and Implementation Strategy}

Urban Planning \& Implementation Strategy [22] elaborates the importance of urban planning in land administration and management. It points out that, since land is finite resource, wise use of this land is fundamental and timely issue. It is through effective land use planning that the value of land is 
scaled up and create enabling environment for socioeconomic developmental endeavors of the government.

Moreover, the strategy reveals that land use plan plays a leading role in strengthen the rural-urban and urban -urban linkage as well as promoting the competitive and comparative advantages of cities in terms of market, services technology and industrialization.

The strategy notes that despite its importance, the urban plan preparation and implementation process of Ethiopia suffers from multifaceted limitations. The common drawbacks observed during plan preparation is less attention paid to manufacturing and storage, factories as well as micro and small enterprise. This in turn leads to scarcity of working and selling premises for factories and MSE. Urban plan preparation process became an obstacle for expansion of new investment through manufacturing in urban centers.

In addition, the existing factories are found mixed with residential areas and are constructed without buffer zone and thus create problems to the society.

The strategy notes that the existing plan preparation and implementation challenges are mainly caused by lack of skill professionals, shortage in number and mix of professionals, lack of commitment by city administrators, lack of information on the amount of land demand for social services, economics activities, manufacturing and rent seeking character and acts of both on professionals and officials. The plan preparation processes that pass through these pressing challenges have resulted in misrepresentation of the existing realities and the prospects of the city.

Besides, there is a gap in coordination among the community, private sectors and government in plan making and implementation process. To this end, the strategy identifies the problems in the involvement of various stakeholders in the various phases plan preparation and their comments are also not incorporated in draft plan. The main factor that inhibits the effective involvement of public is lack of awareness on both the sides of the experts and the community due to the wrong notion that' plan is technical and thus left for professional'. With this in mind, the urban community is discouraged to participate and ask their pressing challenges which demands planning solutions.

Institutions like micro and small enterprise offices are also not actively participated in plan making discussion forums and not expressing their land demand for the construction of clusters and shades for the next ten years.

The strategy document also clearly identifies the existence of low level of awareness of on the community and plan making institution in that the owner of the plan is community itself and thus active involvement in planning process is indispensible for the quality of plans.

Further, it elaborates the existence of poor information exchange among various institutions that have stake with urban planning. There is weak in data organization, management and exchange from Federal to local government. In addition, the system is not supported with data base management.

The strategic document pinpoints the planning principles that will be followed during plan making and implementation process. The principles are enacted with the aim of improving the aforementioned challenges both on the side of plan making institutions and stakeholders. The newly formulated principles are presented as'

1) Prior to plan making, need assessment study must be conducted. Thus, plan making process should incorporate the needs of the developers and support the transformation from Agriculture Development Led Industrialization.

2) The plan preparation and implementation process should ensure transparency, accountability and supported with effective legal documents that protects plan violations

3) Due attention should be paid for compact development in the plan preparation and implementation

4) In plan making process, the physical, social, economic and spatial issues need to be coordinated and targeting at bringing solutions

5) Ensure mixed development that encourages social cohesion

6) Ensure active community and stakeholders participation both during preparation and implementation

7) Ensure the implementation of 30:30 and 40 land use principles in the preparation of plan. This means 30 percent goes for road $\&$ infrastructure, 30 percent for greenery and public utilities and 40 percent for the construction of buildings.

The construction of building includes housing, commerce, worshiping and manufacturing. Greenery and public utilities includes park, open space, public gathering, playground, natural forest, urban agriculture, quarrying places, marshy areas, places for Sunday and informal trades whereas road and infrastructure includes all types of streets, utilities traffic islands etc.

Despite, the strong commitment by the government to curb the prolonged and multifaceted challenges of urban planning and promote the role of city in developmental endeavors, still there seems a conspicuous gap in urban planning principles. For instance, the principles of 30:30 and 40 percent land allocation lacks the clarity. On one hand, MSEs are subdivided in to two categories (both in building under manufacturing and greenery and public utilities under urban agriculture). On the other hand, the weight given to micro and small enterprises is still not clear.

On the other hand, the strategy document clearly states the role played and to be played by metropolitan (Addis Ababa) and seven secondary cities. It elaborates the specific roles to secondary cities of the country as'

Table 5. The new role of cities.

\begin{tabular}{lll}
\hline No & Name of secondary city & The new role to be played as centers of \\
\hline 1 & Dire Dawa & Industrialization \& import/export trade \\
2 & Mekele & Industrialization \\
3 & Hawassa & Industrialization \& Tourism \\
4 & Adama & Service \\
5 & Bahir Dar & Service \\
6 & Jimma & Agriculture and Research \\
7 & Dessisie and kombolcha & Light industries \\
\hline
\end{tabular}

Source: [22] 
The above tasks are delivered to cities with aim of promoting the level of urbanization and scale up their role as an engine of development. The implication is that plan making process should take in to account the specific roles of the cities and thus attention should be paid in assigning land use categories.

(ii) Review of Urban Planning and Implementation Manual

The urban planning and implementation manual of the country was revised by 2012 Ministry of Urban Development and construction. The manual is prepared with the aim of guiding the plan making process and thus incorporates the principles, phases of planning, the actors, manpower composition and level of public participation in plan preparation process. The manual reveals the social, economic, environmental and spatial data types to be collected and the possible sources of the data as well as the methodology adopted during data analysis, interpretation and preparation of proposals.

Further, under economic sector, the manual pinpoints the basic information needed to informal trade and micro and small enterprises. To this end, the number of persons engaged in MSEs, source of raw material or inputs, major products or outputs, extent of inter-sectoral linkage and availabilities of support institutions as well as the type of support provided, potentials and challenges of micro and small enterprises are well presented.

The manual [23] prescribes the possible urban planning principles to be adopted in planning process as'

1) Conformity with the hierarchy of plan

2) Sharing the national vision and standard as well as capability of being implemented

3) Consideration of inter-urban and urban -rural linkages

4) Delineation of spatial framework for urban centers in view of efficient land utilization

5) Ensuring the satisfaction of the need of the society through public participation, transparency and accountability

6) Promotion of balanced and mixed population distribution

7) Safeguarding the community and the environment

8) Preservation and restoration of historical and cultural heritages

9) Balance public and private interests
10) Ensure sustainable development

The principles of urban planning and implementation as stated in the manual have difference as compared with urban planning and implementation strategy.

The urban planning and implementation strategy recognizes the new land use proportion or assignment that planners need to consider in urban planning. It also urges the significance of conducting need assessment study prior to launching urban planning. The manual ignores such principle. This implies the strategy is not well translated in to the ground and thus, there is in compatibilities between strategy and manual, which means there will be challenges during implementation.

Further, the strategy gives due attention to the specific role of a city in preparation of any sort of plan. The notion is that plan making process should not always lie or stick to the planning standards. Rather, the issue of contextualization needs to be considered.

Urban planning and implementation strategy recognizes the specific role each city play and thus classified urban centers by the new role to be played. For instance Hawassa city administration is assigned as a center of industries and tourism and thus the plan making process tend to promote these competitive and comparative advantages of the city. However, the issue of contextualization as one principle is not incorporated in the urban planning and implementation manual which means, according to the manual, the same principles will be applied for all urban centers of Ethiopia irrespective of their growth level and potentials.

\section{(iii) Review of Urban Planning and Implementation Standard}

Urban planning and implementation standard was revised by 2012 Ministry of Urban Development and construction. The standard points out the seven major land use categories and the proportion for four different classes of urban centers. The standard also puts the amount of space or land use needed for micro and small enterprises.

The standard further subcategorizes micro and small enterprises under manufacturing and storage together with that of medium and large industries, whorehouse, depots, workshops and fuel station.

The standard elaborates land use classification and proportion for city like Hawassa as'

Table 6. Proposed percentage of Land use for City.

\begin{tabular}{lll}
\hline No. & Structure plan component & Proposed percentage \\
\hline 1 & Housing & $40-50$ \\
2 & Business and commercial centers and market place & $7-20$ \\
3 & Service, public facilities, cultural, archeological sites and special function & $10-20$ \\
4 & Green recreation sports and environmental sensitive areas & $15-20$ \\
5 & Administration & $3-7$ \\
6 & Manufacturing and storage & $10-15$ \\
7 & Infrastructure, utilities and transportation & $15-25$ \\
\hline
\end{tabular}

Source: [20]

The standard reveals for the percentage for manufacturing and storage (where, MSE is a sub group) varies from 10-15 percent.

On the other hand, the standard limits the total area utilized for manufacturing and storage as' 
Table 7. Standard for manufacturing activities.

\begin{tabular}{|c|c|c|c|}
\hline No. & Standard & Type of manufacturing activities & Area required (in $\mathrm{m}^{2}$ ) \\
\hline 1 & Small scale industry & $\begin{array}{l}\text { Wood\& metal works, garages, mills, handicraft such as ceramic, traditional clothing and } \\
\text { jewellery production, etc }\end{array}$ & $5000-2,500$ \\
\hline 2 & Medium scale industry & Processing plants, packing, etc & $5000-10,000$ \\
\hline 3 & Large scale industry & Flour and textiles, factories.etc & $10,000-15,000$ \\
\hline
\end{tabular}

Source: [20]

As indicated on the table above, the total areas for the three categories of industries are predetermined for any urban centers. The table overlooked two basic issues. One of incompliance is it fails to notice the specific role to be played by the city. The other challenge is it is against to the country's economic and transformational policy and strategies.

The application of the standards during plan making process deters the country plan to accelerate its transformation and expansion of manufacturing industry.

\section{Interpretation and Discussion}

The result of findings have verified the uneven distribution of production and selling places in the city. Working premises contribute only 12 percent of the total establishments. The largest share ( 82 percent) is accounted by selling premise. Premises serving for both production and selling account 5.2 percent.

As far as the distribution of MSEs by construction material is concerned, about 87 percent of the enterprises are constructed either with container, lumber and wood\& mud. Only 12.7 percent of establishments are occupied by clusters and shades.

The study results have portrayed the prevalence of manufacturing subsector in small proportion despite the great concern by the government to promote the manufacturing subsector, it is found in small proportion. Results of analysis through GIS have revealed, out of the total area occupied by MSE, manufacturing contributes only 12.6 percent. It is second to the least (i.e. urban agriculture) which shares 6.4 percent. Operators in manufacturing subsector are confined only in clusters and shades. This is due to the fact that it requires larger production premises as compared to other subsectors of MSE.

Manufacturing subsector is found in lower position as compared to other establishments of Micro and small enterprise. A good manifestation to this fact, as emphasized by the respondents, is the operators in manufacturing sub sectors are forced to pay addition cost for selling premises in central area rented from private individuals. Similarly, as it observed in field survey, the existence of closed buildings within Tabor sub city (cluster closer to new prison). In this cluster, even though, the buildings are distributed for operators, they preferred shutting down and rent the premises from private individuals around central areas.

The result of this research complied with Jemal Abagissa findings in terms of establishments of MSEs in Ethiopia stated as:
"... Trade dominates the MSE with little involvement in the manufacturing sector which is the priority area of the national MSE development strategy." [24]

Thus, shortage of selling premises and the remoteness of existing clusters and shades from market and raw materials have adversely affected the productivity and production and are responsible to their small number.

Moreover, MSEs are placed unplanned way together with other establishments. As it has been indicated in previous sections, 83 percent of MSEs are found either along street, with in Lake Buffer and within the space reserved for green. The percentage of unplanned expansion outweighs the existing (i.e. 83) percent if the production premises are excluded. Out of the total selling premises, 90.2 percent of are situated in unplanned manner. The preposition is that the assignment of working and selling premises for MSEs are carried out arbitrary and unplanned manner on public spaces. The result of the analysis coincides with the statement made by Berihun Asefa [13] stating the problems of MSE are not only shortage of working premises but also they are built arbitrarily.

The study results have confirmed that most of the premises of Micro and small enterprises are built on a temporal base and lacks sustainability. Despite, the essential and sustainable option in provision of working and selling premises adopted by government is construction of shades and clusters by its own and apportion to enterprises rather than delivering land, the existing realties are not in favor of this idea. About 87 percent of the enterprises are constructed on a temporal way and are either with container, lumber and wood \& mud. On the other hand, the findings have uncovered, the emphases of local administrators have a tendency to provide temporal solution other than permanent ones. Even if the significant contribution in minimizing the shortage of selling premises, the temporal alternatives have adverse impacts on the city. This implies the existence of clear gap between policy options and actual implementation in the provision of premises for MSE.

The finding the study confirms the Micro and small Enterprise Agency report stating:

"Site selection for MSE production and sales facilities built by some urban local government were not guided by urban plans. Many were built using poor building designs on sites that lacked title deed, many did not have access to basic infrastructure and services (water and electricity), had inadequate provision of land and built structures were not designed to industry specific requirements." [16]

It is not uncommon to expect adverse consequences from arbitrarily placed MSE. Unplanned expansion of MSE is 
becoming the potential threat to the city. The preceding findings have revealed that the prevailing unfavorable consequences of MSE to be unpleasant scene, obstructing pedestrian movement and traffic flow. Good evidence to this fact is the presence of enormous amount of MSEs (service subsector) closer to Lake Hawassa. These establishments are constructed on the cost of recreational places by reducing aesthetic scene of the lake and thus create discomfort for tourists. If unchecked, it will have undesirable effect on tourism sector by reducing leisure time in the lake to the specific and in the city in general. Likewise, those premises constructed with substandard materials and situated along streets have negative impacts on city's competitive environment. The findings have shown 70 percent of working and selling premises are negatively affecting the aesthetic scene of the city. To this end, those premises constructed from containers, plastics and woods contribute to largest share in reducing the aesthetic value of the city.

The overwhelming majorities (79 percent) of the premises are established on sidewalks and it became the common phenomena to observe the adverse effects of MSEs on pedestrian movement. In these areas the sidewalks are either partially or fully obstructed.

To examine the level of compatibility, two fundamental criteria are taken in to account. The first criterion is crosschecking the existing location of MSE with Integrated Development Plan and thus evaluates the level of conformity. The second criterion is reviewing the plan making process with respect to urban planning and implementation manual and standard.

The results of analysis have confirmed 92 percent of the existing working and selling premises are incompatible as compared to Integrated Development Plan of Hawassa and only 8 percent are constructed according to the plan. One of the testimonies of incompatibilities is the violation of open space and/or public spaces. Most of MSEs are located on the sides of the streets obstructing pedestrian movement and in turn makes the people to use the main asphalt together with vehicles. It has adverse effects such as disturbing the circulation and creates traffic accident. The predominance of incompatibilities connotes unplanned expansion of MSEs in the city.

Likewise, the overwhelming majority of the Micro and small enterprises are placed together with service and green frame as opposed to the revised Urban Planning Preparation and Implementation standard, which urges MSEs could not be located closer to service and green frames. The implication is, in the process of expanding MSEs, adjacent land use conflict is found to be serious and demand due attention.

As far as the policy response to the existing challenges of premises for MSEs concerned, the government of Ethiopia has so far made relentless effort to enact full-fledged policies, strategies, rules, regulations and manuals towards expansion of MSE. This acknowledges its commitment to promote the sector in sustainable manner. However, the policy formulation and implementation process has practical gaps.
Despite the detail elaboration of policy directions towards Micro and small enterprises, there is an inconsistency between Urban Development policy and Micro and small enterprises strategy. For instance the Micro and small enterprises strategy inhibits the delivery of barren land for micro and small operators. However, the policy allows delivery of developed land for operators on a lease base as an alternative to the construction of clusters and shades by government.

On the other hand, the MSE strategy sort outs the challenges in detail by classifying Micro and small enterprise in to three categories based on maturity levels (start up, growth and maturity stages). The challenges at growth and maturity stages are lack of working and selling premises, lack of capital, lack of accounting, business management, lack of skills and techniques. But it reveals the challenges at lunching or start up stage to be lack of capital, lack of accounting, business management, lack of skills and techniques. The strategy ignores the working and selling premises as the major challenges at lunching stage. However, the discussion with operators and key informants uncovered working and selling premises as the critical challenges at lunching stage.

Despite, the strong commitment by the government to curb the prolonged and multifaceted challenges of urban planning and promote the role of city in developmental endeavors, still there seems a conspicuous gap in urban planning principles as stated in urban planning and implementation strategy.

The study made by Gebrehiwot Ageba and Wolday Amha supported the existence of challenges in regulatory framework as:

"Concrete and coordinated regulatory and institutional support has yet to be provided by the government and other stakeholders and it imply a need to revisit the legal, regulatory and institutional framework in the country within which MSEs operate" [25].

For instance, the principles of 30:30 and 40 percent land allocation lacks the clarity. On one hand, MSEs are subdivided in to two categories (both in building under manufacturing and greenery and public utilities under urban agriculture). On the other hand, the weight given to Micro and small enterprises is still not clear.

Likewise, the urban planning and implementation strategy recognizes the new land use proportion or assignment that planners need to consider in urban planning. It also urges the significance of conducting need assessment study prior to launching urban planning. Whereas the manual ignored such principles. This implies the strategy is not well translated in to the ground and thus, there is in compatibilities between strategy and manual, which in turn means there will be challenges during implementation.

Further, the strategy gives due attention to the specific role of a city in preparation of any sort of plan. The notion is that plan making process should not always lie or stick to the planning standards. Rather, the issue of contextualization needs to be considered. To this end, the strategy recognizes the specific role each city play and thus classified urban 
centers by the new role to be played. For instance Hawassa city administration is assigned as a center of Industries and tourism and thus the plan making process tend to promote these competitive and comparative advantages of the city. However, the issue of contextualization as one principle is not incorporated in the urban planning and implementation manual which means, according to the manual, the same principles will be applied for all urban centers of Ethiopia irrespective of their growth level and potentials.

On the other hand, urban planning and implementation standard limits the total area utilized for manufacturing and storage by classifying in to three groups (small, medium and large Industries) and allocate the total area for Small scale industry to be with the range of $5000-2,500 \mathrm{~m}^{2}$ no matter what level and role of cities. It is obvious that implementing the standards means violating the policies and strategies.

\section{Conclusions}

The main objective of the research is to examine the role of urban land use in the perspective of Micro and small enterprises development in Hawassa city. In this regard, the existing spatial distributions, issues of compatibility with land use land as well as reviews of policy response to MSEs are the main focal areas of the research. Based on the findings and discussions, the following conclusions are made;

1) The findings portray manufacturing subsector is found in small proportion. Despite the great concern by the government to promote the sector, it is found in small proportion. Out of the total area occupied by MSEs, manufacturing contributes only 12.6 percent in terms of establishments. Furthermore, the shortage of working and selling premises as well as the remoteness of existing clusters and shades from market and raw materials are the major challenges that deter their growth.

2) The assignment of working and selling premises for MSEs are carried out arbitrary and unplanned manner on public spaces. As it is indicated in previous sections, 83 percent of MSEs are found either along street, with in Lake Buffer and within the space reserved for green frame.

3) Despite, the essential and sustainable option in provision of working and selling premises adopted by government is construction of shades and clusters by its own and apportion to enterprises rather than delivering land, the existing realties are not in favor of this idea. About 87 percent of the enterprises are constructed on a temporal way and are either with container, lumber and wood \& mud. This implies the existence of clear gap between policy options and actual implementation.

4) As far as the land use plan of the city is concerned, the results of analysis confirms 92 percent of the existing working and selling premises are incompatible as compared to Integrated Development Plan of Hawassa.
Most of MSEs are located on the sides of the streets and this implies their establishment obstructs pedestrian movement and in turn makes the people to use the main asphalt together with vehicles. The predominance of incompatibilities connotes unplanned expansion of MSEs in the city.

5) The overwhelmed majority of the Micro and small enterprises are placed together with service and green frame as opposed to the revised Urban Planning Preparation and Implementation standards that urges MSEs could not be located closer to service and green frames. The implication is in the process of expanding MSEs, adjacent land use conflict is found to be serious and demand due attention.

6) Inconsistency was also observed in plan making process of the city. The existing land use plan did not comply with planning manuals and standards. The percentage assigned in land use plan for manufacturing \& storage is 4.4 , which is much lower as compared to the urban planning manual and standards (10-15percent for cities like Hawassa). Moreover, the plan did not put area or percentage for MSE. This negligence is the core factor that restrains and adversely affects the economic growth of the sector by discouraging competitive and comparative advantage (industrialization \& tourism) of the city.

7) As far as the policy response to the existing challenges of premises for MSEs concerned, there is inconsistency between Urban Development policy and Micro and small enterprises strategy. For instance the Micro and small enterprises strategy inhibits the delivery of barren land for micro and small operators. Whereas, the policy allows delivery of developed land for operators on a lease base as an alternative to the construction of shades by government.

8) The MSE Strategy ignores the working and selling premises as the major challenges at lunching stage. However, the discussion with operators and key informants disclose working and selling premises as the critical challenges at lunching stage.

9) Still there seems a conspicuous gap in urban planning principles as stated in urban planning and implementation strategy. For instance, the new land use proportion (30:30 and 40 percent) lacks the clarity

10) Urban planning and implementation strategy gives due attention to the specific role of a city in preparation of any sort of plan. The notion is that plan making process should not always lie or stick to the planning standards. The issue of contextualization needs to be considered. However, the issue of contextualization as one principle is not incorporated in the urban planning and implementation manual which implies the strategy is not well translated in to the ground and thus, there is in compatibilities between strategy and manual and thus, challenges during implementation is inevitable.

11) Urban planning and implementation standard limits the total area utilized for manufacturing and 
storage and allocate the total area for Small scale industry to be with the range of $5000-2,500 \mathrm{~m}^{2}$, irrespective of the level and role of cities. It is obvious that implementing the standards means violating the policies and strategies.

\section{Recommendations}

Many literatures confirm that urban planning has strong power to kill or give life to city. Urban planning in turn is influenced by the existing political environment, the skill of professionals and administrators. Besides, effective urban planning requires active involvement of public and private sectors. Therefore, the plan making and implementation process should give room for public and private sectors such as community and MSE. Besides, the innovative approach to the challenges related to Micro and small enterprises need to be followed. Sustainable solution for MSE focuses on revising of policy and regulatory frame works. This approach is recommended for the regional and Federal Government that has the responsibilities of policy and regulatory formulation. The following recommendations are forwarded to scale up the role of urban planning in promoting Micro and small enterprises development and ensure compatibilities of land uses in sustainable manner.

1) New urban planning principle stated as" promoting of MSE "need to be incorporated in urban planning manual and standard.

2) Revision of standardization for the seven land use category according to the role of the city is basic and a timely issue.

3) Coordination among plan preparing and implementing bodies are decisive.

4) The location of MSE should be assigned according to land use plan and based on economic impact assessment

5) Provision of premises for MSEs at launching stage is fundamental issue that determines productivity and profitability.

6) Capacity building program on urban planning and implementation for officials and professionals are vital to ensure plan quality

7) Incorporation of the issues of MSE in re-developmental area is a shortcut to enhance local economic development.

\section{Request for Further Study}

Urban issues are complex and dynamic and thus demand flexible, context based and innovative urban planning approaches. Which in turn requires continues improvement of planning principles and standards for urban plan. This research did not cover the standardization of the land use categories or functions. Therefore, further researches are acknowledged on setting context-based standards and principles the proportion of land use function of cities.

\section{References}

[1] Scholar, W. W. (2007). Global Urban Poverty. Washington D.C: Woodrow Wilson International center for scholar.

[2] SEAF. (2007). From poverty to prosperity: Understanding the impact of investing in small and medium enterprises. Washgton D.C: SEAF.

[3] Vandenberg, P. (2006). Poverty Reduction through Small Enterprises. Geneva: International Labor office: Small Enterprise development Program.

[4] United Nations (2018), Economic and Social Council.

[5] United Nations, (2015). Transforming the World: The 2030 Agenda for Sustainable Development.

[6] OECD (2017). Enhancing the contribution of SMEs in a Global and Digitalized Economy: Better Economy for better lives. Paris.

[7] World Bank (2017) Finance gap: Assessment of the shortfalls and opportunities in financing micro, small and medium enterprises in emerging markets. Washington.

[8] Commision, E. (2013). A recovery on the Horrizon: Annual report on Eroupean SMES. Berlin: Eroupean Commision.

[9] University, p. \&. (2014). The socioeconomic contribution of small scale industries to livelyhood of women in the Shea Butter Industry. European Scientific journal, 10, 17.

[10] Abera, A. (2012). Factors affecting the performance of MSE in Arada \& Lideta. Addis Ababa: Addis Ababa University.

[11] Tereda, B. (2014). The assessement of factors that affect the growth and sucess of MSEsin Guraghe zone in three selected woredas. Dilla: Dilla University.

[12] Agency, F. M. (2015, January). Cities are Engies of Enterprises. Addis Ababa: Agency, Federal Micro and Small Enterprises.

[13] Berihun Assefa, A. Z. (2014). Identifyingkey sucess factors and constraints in Ethiopia's MSE development: An exploratory Research. Addis Ababa: Ethiopian Development Research Institute.

[14] Agency, F. M. (2013). Survey on Micro and Small Enterprises (MSE) in selected major cities of Ethiopia. Addis Ababa: Ministry of Urban Development \& Construction.

[15] Gebereeyus, M. (2007). Growth of Micro-Enterprises: Empirical evidence from Ethiopia. Addis Ababa: Ethiopian Research Institute.

[16] Construction, M. o. (2013). Micro and small Enterprise Development strategy. Addis Ababa: Ministry of Urban development housing and Construction.

[17] Department, H. T. (2014). Micro \& small Enterprise. Hawassa: Trade \& Industry Department.

[18] Agency, C. S. (2012). Population Projection. Addis Ababa: Central Statistical Agency.

[19] Department, H. T. (2015). GTP performance report. Hawassa: Unpublshed report. 
[20] Ministry of Construction, H. a. (2013). The revised Urban Plan Preparation and Implemtation Standards. Addis Ababa: Ministry of Construction, Housing and Urban Development.

[21] Ministry of Construction, H. a. (2013). The revised Urban Development Policy. Addis Ababa: Ministry of Construction, Housing and Urban Development.

[22] Construction, M. o. (2013). Urban plan preparation and implementation strategy. Addis Ababa: Ministry of Urban development housing and Construction.

[23] Ministry of Construction, H. a. (2013). The revised Urban
Plan Preparation and Implementation Manual. Addis Ababa: Ministry of Construction, Housing and Urban Development.

[24] Jemal Abagissa (2021). The Assessment of Micro and Small Enterprises Performance and Challenges in Addis Ababa. International Journal of Applied Economics, Finance and Accounting.

[25] Gebrehiwot Ageba and Wolday Amha (2001). Micro and Small Enterprises Development in Ethiopia: Strategy, Regulatory Changes and Remaining Constraints. Journal of Economics. 